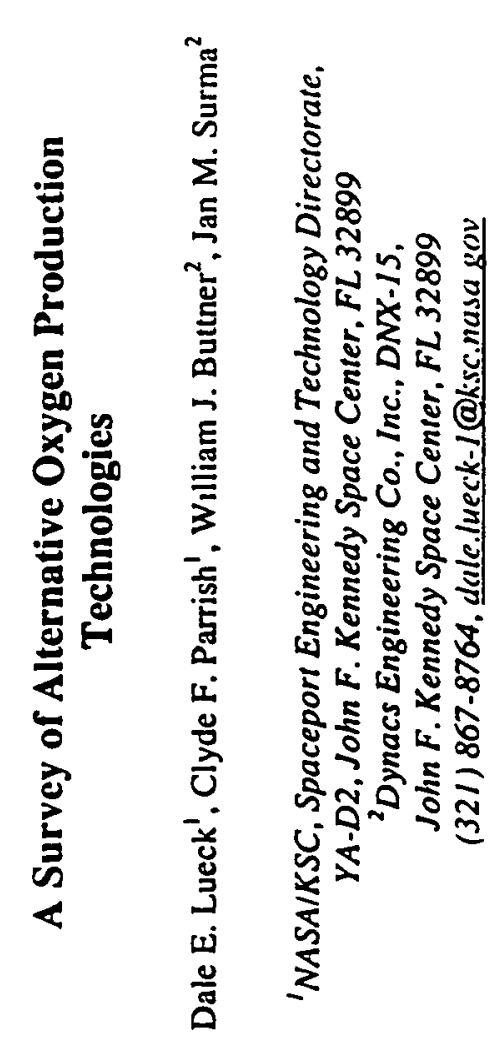

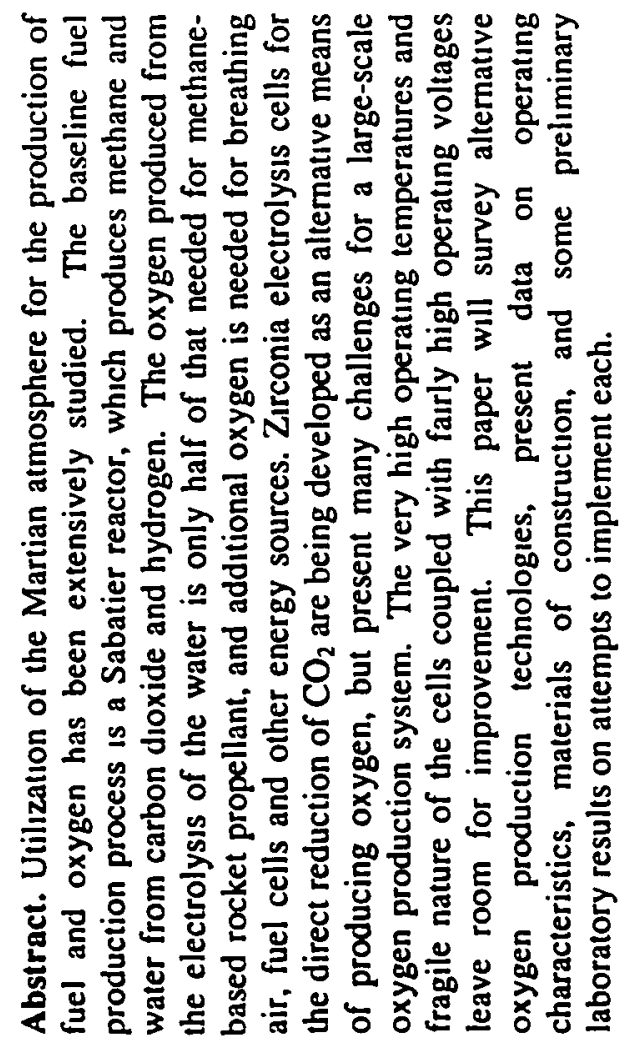

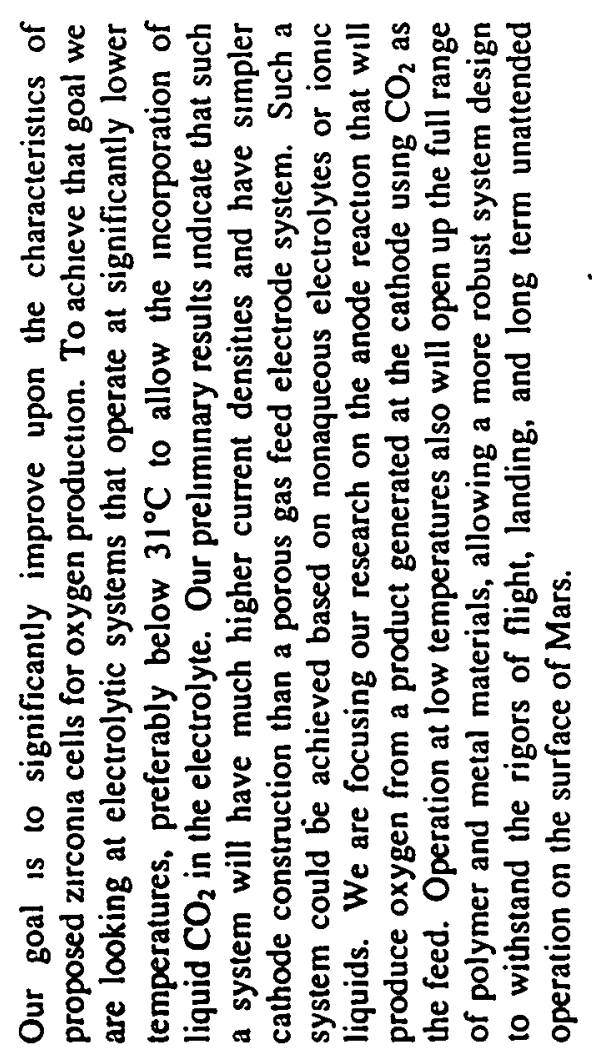




\title{
A Survey of Alternative Oxygen Production Technologies
}

\author{
Dale E. Lueck ${ }^{1}$, Clyde F. Parrish', William J. Buttner ${ }^{2}$, Jan M. Surma ${ }^{2}$ \\ 'NASA/KSC, Spaceport Engıneering and Technology Directorate, YA-D2. \\ John F Kennedy Space Center, FL 32899 \\ ${ }^{2}$ Dynacs Engineering Co., Inc., DNX-15, John F. Kennedy Space Center, FL 32899 \\ (32J)867-8764, dale.lueck-1@ksc.nasa.gov
}

\begin{abstract}
Utlization of the Martian atmosphere for the production of fuel and oxygen has been extensively studied. The baseline fuel production process is a Sabatier reactor, which produces methane and water from carbon dioxide and hydrogen. The oxygen produced from the electrolysis of the water is only half of that needed for methane-based rocket propellant, and additional oxygen is needed for breathing air, fuel cells and other energy sources. Zirconia electrolysis cells for the direct reduction of $\mathrm{CO}_{2}$ are being developed as an altemative means of producing oxygen, but present many challenges for a large-scale oxygen production system. The very high operating temperatures and fragle nature of the cells coupled with fairly high operating voltages leave room for improvement. This paper will survey altemative oxygen production technologies, present data on operatıng characterıstıcs, materials of construction, and some preliminary laboratory results on attempts to implement each
\end{abstract}

\section{BACKGROUND}

In-Situ Resource Utulization (ISRU) is one of the enabling technologies for HEDS (Human Exploration and Development of Space) missions. For a HEDS mission to Mars, an ISPP (In-Situ Propellant Production) plant is a key technology for manufacturing the fuel and oxygen required for a Mars ascent vehicle, surface power, and life support. The combination of a Sabatier reactor and water electrolysis has become the baseline technology for fuel production, producing methane and oxygen through the following reactions:

$$
\begin{aligned}
\mathrm{CO}_{2}+4 \mathrm{H}_{2} & \leftrightarrow \mathrm{CH}_{4}+2 \mathrm{H}_{2} \mathrm{O} & & \text { (Sabatier Reaction) } \\
2 \mathrm{H}_{2} \mathrm{O} & \leftrightarrow 2 \mathrm{H}_{2}+\mathrm{O}_{2} & & \text { (Electrolysis of Water) }
\end{aligned}
$$

The $\mathrm{CO}_{2}$ is taken from the Mars atmosphere $\left(95 \% \mathrm{CO}_{2}\right)$ and the $\mathrm{H}_{2}$ is brought from Earth. The Oxygen produced is only half of what is needed to combust the methane produced in this process. Therefore, a supplemental oxygen production technology is needed. Direct electrolysis of $\mathrm{CO}_{2}$ is possible and this process has been studied extensively using zirconia electrolysis cells. Zirconia is a ceramıc material that becomes conductive at high temperatures, and will transport oxygen ions through the lattice under the influence of an applied electric field. At temperatures around $900^{\circ} \mathrm{C}$, substantial currents can be obtained, and carbon dioxide can be reduced as follows:

$$
2 \mathrm{CO}_{2} \leftrightarrow 2 \mathrm{CO}+\mathrm{O}_{2} \quad \text { (Electrolysis of Carbon Dioxide) }
$$

The Zirconia membrane has porous electrodes in intımate contact with each side, and this membrane separates the two product gases (carbon monoxide and oxygen). Zirconia is quite fragile to thermal or mechanical shock, particularly in the thin membranes used in these cells to lower the resistance and decrease resistive losses in the cell. The very high temperatures of operation limit materials to ceramics, as most base metals are quickly oxidized at these temperatures with high oxygen concentrations. Any crack in the membranes (multi-layered cells are required for large scale production) will result in contamination of the product oxygen with carbon dioxide, or carbon monoxide if the leak occurs at low temperature. Such contamination would render the oxygen unsuitable for 
breathing atr, one of its intended uses. Lastly, the Zirconia cell operates at about 1.6 volts, consuming about $50 \%$ more energy than theoretically required for this reduction. If the operating potential of this, or any other $\mathrm{CO}_{2}$ electrolysis cell, can be reduced, the energy utilization can be substantially improved.

\section{ALTERNATIVE OXYGEN PRODUCTION TECHNOLOGIES}

Oxygen can be obtained from carbon dioxide through one of two direct reaction paths. One is shown in Equation (3) above, and the other is:

$$
\mathrm{CO}_{2} \leftrightarrow \mathrm{C}+\mathrm{O}_{2}
$$

In Equation (4), the product obtained is carbon instead of carbon monoxide, and only half as much carbon dioxide is required, to produce a set quantity of oxygen, as in Equation (3). Elther reaction can be obtained through direct electrolysis or a chain of chemical reactions. The later methods often involve a series of reactions that produce water, which is electrolyzed, while the hydrogen is recycled to react with more carbon dioxide. Both direct electrolysis and cyclic reactions could produce oxygen more efficiently and at lower temperatures than a Zirconia cell. Many of these techniques allow a greater choice of construction materials, resulting in a more rugged and reliable assembly.

\section{Desiccant-Electrolysis/RWGS}

The Reverse Water Gas Shift (RWGS) is the catalytic reduction of $\mathrm{CO}_{2}$ by $\mathrm{H}_{2}$ to produce $\mathrm{CO}$ and $\mathrm{H}_{2} \mathrm{O}$

$$
\mathrm{CO}_{2}+\mathrm{H}_{2} \leftrightarrow \mathrm{CO}+\mathrm{H}_{2} \mathrm{O} \quad \text { (RWGS reaction) }
$$

The RWGS can be made into a cyclic reaction of hydrogen and carbon dioxide by combining the processes described by Equation (5) with those of Equation (2). Recycling the hydrogen makes the combined reactions capable of producing an infinite amount of oxygen providing there is no loss of hydrogen (an unrealistic assumption). The net equation for this process is the same as Equation (3), with the electrolysis of water being substituted for the direct electrolysis of carbon dioxide. This process runs well at a temperature of $375^{\circ} \mathrm{C}$, but the equilibrium constant for Equation (5) is only about 0.1. To drive this reaction to completion, the products (e.g., water and $\mathrm{CO}$ ) are removed from the gas stream with a dropout cooler and a selective membrane for $\mathrm{CO}$ separation. The gas mixture, enriched with unreacted $\mathrm{CO}_{2}$ and $\mathrm{H}_{2}$, is fed back into the RWGS reactor. Approximately 10 cycles are necessary for the efficient conversion of the incoming carbon dioxide to carbon monoxide and water. Electrolysis of the water (Equation 2) renews the hydrogen supply, allowing a constant input flow of carbon dioxide to enter. This process is rugged and reliable, but the recycle loop and product separation require both temperature and pressure drops that must be restored as the product mixture re-enters the reactor. This increases the energy input to the system, making the overall process less efficient than zirconia electrolysis.

One way to overcome these problems is to remove the water formed in Equation (5) directly in the reactor, thereby forcing the reaction to completion and elıminating the energy intensive recycle loop. This can be accomplished with a desiccant system that could operate at the reactor temperature coupled with direct electrolysis of the product water to regenerate the hydrogen for the reaction. A desiccant electrolysis cell was constructed using a ceramic felt saturated with concentrated (85\%) phosphoric acid as an electrolyte sandwiched between two platinum gauze electrodes. Using a DC voltage, the cell was electrolyzed under a dry nitrogen purge to remove water and to create a desiccant. At this point a nitrogen stream saturated with water vapor was introduced into the cell. When the humidified nitrogen stream was admitted to the cathode side, no appreciable current flowed. If the moist gas stream was introduced into the anode chamber, a much larger current was produced, and the relative humidity of the exiting gas stream was reduced. The generation of hydrogen and oxygen by water electrolysis was confirmed by mass spectrometric analysis of the exiting nitrogen carrier gas streams from the cathode and anode, respectively. 
This series of tests indicate that the water vapor must be admitted at the anode for efficient electrolysis. This makes sense because the cathode reaction is the reduction of hydrogen ions to hydrogen gas, while the anode reaction is the direct oxidation of water to produce oxygen and hydrogen ions. Oxygen generation causes the electrolytic connection to the anode to be lost as the water is consumed. Moreover, onentation of the anode at the reaction mixture interface is contrary to the requirements for coupling the electrolysis to the RWGS reactor. Hydrogen gas, which must be retumed to the reaction mixture, is generated at the cathode, while oxygen needs to be removed from the reaction zone. This problem, coupled with the fact that the anhydride $\left(\mathrm{P}_{2} \mathrm{O}_{5}\right)$ was not formed during electrolysis means that the desiccant properties would be reduced and the ability to drive Equation (5) to the right would be reduced. Further work to couple this process with RWGS has been halted, while we explore other avenues of getting a desiccant in intımate contact with the RWGS reaction. However, the process as described may prove useful for the continuous drying of oxygen streams.

\section{Molten Carbonate Electrolysis}

Molten carbonate electrolysis cells have been previously developed for the removal of carbon dioxide from spacecraft cabin air (Arnoldi, 1966; Janz, 1967). The earlier design formed a carbon cake in the molten salt bath, which would have to be removed and replaced to keep the process operational. This design would present some problems for an autonomous system intended to produce $30,000 \mathrm{~kg}$ of oxygen. A more easily maintained system, given the $600^{\circ} \mathrm{C}$ operating temperature, is to form $\mathrm{CO}$ (carbon monoxide) as the cathode product, and oxygen as the anode product. With such an all gas reactant and product stream, the matenals handling would be more straightforward. This would duplicate the overall reaction in a zirconia cell (Equation 3), but at a lower temperature and possibly at a lower voltage. Whether the cathode product is $\mathrm{C}$ or $\mathrm{CO}$ seems to be affected by the salts used in the melt, the electrode material, and the operatıng temperature (Janz, 1967).

-

Among the disadvantages of molten salt baths are that the separation of oxygen from the other products is dependant upon a liquid seal formed by the molten salt. This type of system cannot achieve very high output pressures, and must be operated with low differential pressures between anode and cathode. The operating temperatures for these cells also precludes any possibılity of liquid $\mathrm{CO}_{2}$ introduction, and thus would require porous electrodes for gaseous $\mathrm{CO}_{2}$ introduction, and the establishment of a three phase interface at the cathode between the electrode, the molten electrolyte and the gaseous $\mathrm{CO}_{2}$ feed stock The anode reaction is also an area of concern. A straightforward oxidation of carbonate (Equation 6) would produce a mixture of oxygen and $\mathrm{CO}_{2}$ at the anode, requiring further separation before use.

$$
2 \mathrm{CO}_{3}^{-2} \leftrightarrow 2 \mathrm{CO}_{2}+\mathrm{O}_{2}+4 \mathrm{e}^{-} \quad \text { (Anodic oxidation of carbonate) }
$$

A better reaction scheme would involve an oxide ion intermediate. The anode reaction would result in the production of pure oxygen through the oxidation of the oxide ion (Equation 7). This requires that an ionized oxide salt, such as lithium oxide, be added to the melt (Amoldi, 1966, Kanzaki, 1975).

$$
2 \mathrm{O}^{-2} \leftrightarrow \mathrm{O}_{2}+4 \mathrm{e}^{-} \quad \text { (Anodic oxidation of oxide ion) }
$$

At the time of this paper, we have just begun our examination of molten salt electrolysis, and we have electrochemical evidence for the reduction of carbon dioxide.

\section{Ionic Liquids}

A large number of molten salts have melting points considerably lower than the molten carbonate system described above. Indeed, there exist one class of ionic compounds having melting points near room temperature and these are referred to as room temperature ionic liquids (RTIL). RTILs would eliminate the power requirement associated with high temperature molten salts. Typical examples of RTIL are N-alkylpyridinium and 1-alkyl-3-methylimidazolium salts, and alkylated thiazolium salts, and amide melts with nitrates to name a few examples (Welton, 1999). RTILs will be evaluated for their ability to electrolyze $\mathrm{CO}_{2}$ at lower temperatures. RTILs can be synthesized to produce 
specific characteristics, such as solvation of $\mathrm{CO}_{2}$ (Blanchard, 1999) or a broad electrochemical window (Rogers. 2000). If a soluble oxygen-producing anion can be added, an electrolytic system for $\mathrm{CO}_{2}$ reduction to oxygen can be developed with RTILs.

\section{Nonaqueous Solvent Electrolysis}

In electrolysis, the potentıal limits of an electrode are established, in part, by the limits of oxidation and reduction of the solvent and electrolyte system used. In aqueous system, the limits are set by the reduction and oxidation of water to produce hydrogen and oxygen, respectively. The reduction of $\mathrm{CO}_{2}$, in general, proceeds at a more cathodic potential than for the reduction of water to hydrogen. Although varying the electrode material to obtain a favorable overpotential difference between these two reductions is possible, the elımination of water from the solvent system employed can eliminate the possibility of a competing water reduction completely. Besides the molten salt electrolysis, which is also a nonaqueous system, there are several solvent system that have been used with much wider electrochemical windows (the potentals between anodic and cathodic breakdown of the solvent) that could be employed to easily reduce $\mathrm{CO}_{2}$. An important property of any electrochemical solvents is the dielectric constant. The dielectric constant determines the solvent's ability to dissolve and ionize a suitable electrolyte. Three such solvents and water are compared in Table 1, adapted from Aurbach (1999)

TABLE 1. Selected Properties of Some Non-Aqueous Solvents and Water.

\begin{tabular}{|c|c|c|c|c|}
\hline Property & Acetonitrile & Dimethyl Sulfoxide & Propylene Carbonate & Water \\
\hline Structure & $\mathrm{H}_{3} \mathrm{C}-\mathrm{CN}$ & $\left(\mathrm{H}_{3} \mathrm{C}\right)_{2}-\mathrm{S}=\mathrm{O}$ & $\mathrm{H}_{3} \mathrm{C}-\mathrm{CH}-\mathrm{CH}_{2}-\mathrm{O}-\mathrm{C}=\mathrm{O}$ & $\mathrm{H}-\mathrm{O}-\mathrm{H}$ \\
\hline Dielectric Constant, $\varepsilon_{\tau}$ & 35.95 & 46.45 & 64.4 & 80.10 \\
\hline $\mathrm{MP},(\mathrm{K})$ & 224.4 & 291.7 & 218.62 & 273.15 \\
\hline $\mathrm{BP},(\mathrm{K})$ & 354.8 & 462.2 & 515 & 373.15 \\
\hline Electrochemical window, (V) & 4.6 & 4.4 & 4.5 & 1.3 \\
\hline Anodic (vs sat'd $\mathrm{Ag} / \mathrm{AgCl}$ ), (V) & +1.4 & +0.7 & +1.3 & +1.10 \\
\hline Cathodic (vs sat'd $\mathrm{Ag} / \mathrm{AgCl}$ ), (V) & -3.17 & -3.71 & -3.18 & -.20 \\
\hline
\end{tabular}

From the table we can see that there are many tradeoffs in characteristics of these solvents. The solvents chosen are aprotic. They cannot be easily reduced to yield hydrogen. They have reasonably wide electrochemical windows, allowing the reduction of carbon dioxide without interference from electrolytic breakdown of the solvent. Notably, none of them has a dielectric constant as high as water. They will not produce solutions with high concentrations of 1onized electrolytes. However, they can operate at low temperatures, where liquid $\mathrm{CO} 2$ can exist, and dissolve enough electrolytes to produce appreciable conductivity. Liquid $\mathrm{CO} 2$ is highly soluble in these solvents (Taylor, 1996). Therefore, we can produce conductive solutions with these solvents, which have very high molar concentrations of carbon dioxide.

However, there are serious problems in the use of such solvent systems. Very little work has been done on $\mathrm{CO} 2$ reduction in these solvents. Often the conductivity of their solutions is lower than that of water based electrolytes by an order of magnitude or more. This will lead to high resistance drops and inefficiencies as we attempt to move towards a mass electrolysis cell with high currents. Even less work has been done on electrolytes for these solvents that could release oxygen at the anode. This latter problem has been our most difficult in investigating these systems. We have electrochemical evidence of carbon dioxide reduction in these solvents, but only when we setup a sacrificial anode reaction that allows current to flow. We have yet to come up with a soluble ionized species that will produce oxygen at the anode. Typical products of carbon dioxide reduction such as formate or carbonate either do not produce oxygen at the anode, or are not soluble in these solvents. We are looking into alkalı metal oxide salts as an alternative.

\section{Liquid Carbon Dioxide}

Although liquid carbon dioxide is a fine solvent for many applications, it is not very useful as a solvent for electrolytic processes. The very low dielectric constant $\left(\varepsilon_{\mathrm{r}}-1.45\right)$ does not allow ionization of any suitable 
electrolyte. As the primary input reactant to a Mars oxygen generator, it is desirable to achieve as high a concentration of $\mathrm{CO}_{2}$ at the cathode as possible. Using a typical porous electrode for gas introduction into an electrolysis cell requires a high tech construction that has taken many years to develop successfully for use in aqueous systems. These electrodes must retain the solvent through surface tension while maximizing the area of contact between the electrode, a thin film of the electrolyte, and the input gas stream. The production of a gaseous product ( $\mathrm{CO}$ is possible via Equation 3 ) only complicates the design problem by creating a diffusion barrier of nonreactant gases at the electrode. Such electrodes utilize only a small fraction of the potential electrode area due to the requirement for three-phase contact at the electroactive sites. A conventional electrolysis cell design can be employed if $\mathrm{CO}_{2}$ is a component of the electrolyte. Fortunately, $\mathrm{CO}_{2}$ !s an excellent co-solvent for the non-aqueous and ionic liquid system discussed above. This allows us to achieve concentrations of 5 Molar or more in solution, instead of $0.04 \mathrm{M} / \mathrm{L}$ for pure $\mathrm{CO}_{2}$ gas, or even lower concentrations for gas bubbled through the solvent. Using a solvent system with high $\mathrm{CO}_{2}$ solubility allows us to pressunze the electrolysis vessel and achieve $\mathrm{CO}_{2}$ concentrations in the electrolyte that vary from milli-molar to multi-molar concentrations, as long as the temperature is below the critical temperature for $\mathrm{CO}_{2}(304.13 \mathrm{~K})$. This gives us great flexibility in optımizing the current density and reduction rate in these cells. It also creates a problem of separating any gaseous products of the cell from the feed carbon dioxide. For the cathode reduction of $\mathrm{CO}_{2}$ it is possible to form solid carbon via Equation 4, instead of $\mathrm{CO}$ as in Equation 3, and thereby eliminate the gas separation problem at this electrode. It would be desirable to utilize a separation membrane for isolating the anode where the oxygen is being produced. This membrane would have to be able to transport the oxygen producing electroactive species, while blocking the flow of carbon dioxide to the anode compartment. To our knowledge, no such membrane currently exists, and we haven't identified an electroactive species that is suitable for such a cell. The oxygen could be separated from carbon dioxide in a postprocessing step, recycling the $\mathrm{CO}_{2}$ back into the electrolysis cell. Experiments with mixed solvents have confirmed increasing cathodic current with increasing partial pressures of dissolved gaseous $\mathrm{CO}_{2}$ in a mixed solvent system. The results are shown in Figure 1.
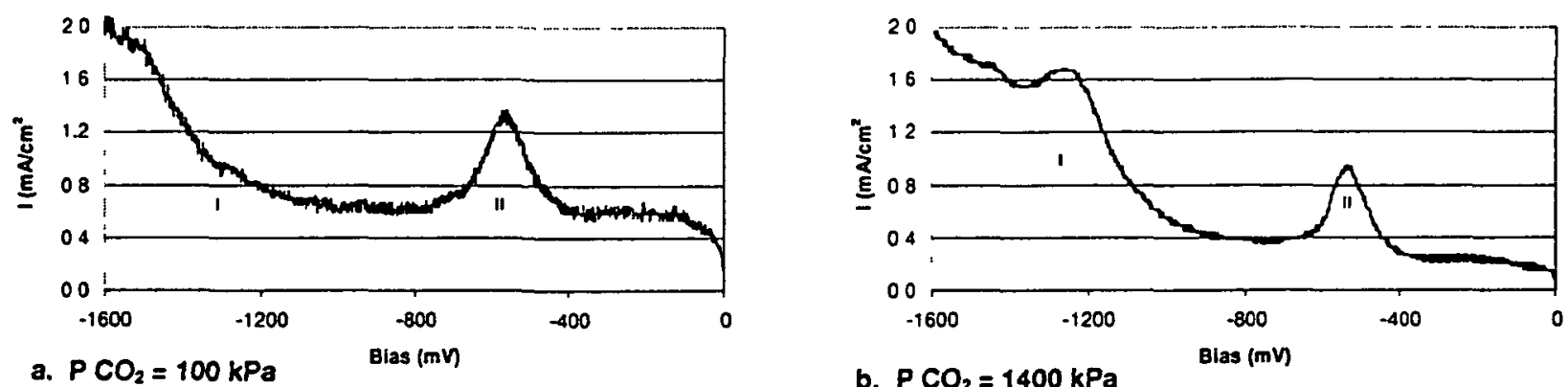

FIGURE 1. Current-voltage curves for the room-temperature electrochemical reduction of $\mathrm{CO}_{2}$ at ambient pressure and at elevated pressure in acetonitrile as measured by linear sweep voltammetry. Two current excursions are observed. " 1 " is the electrochemical reduction of $\mathrm{CO}_{2}$ (pressure dependent), while " $\mathrm{"} \mathrm{is} \mathrm{the} \mathrm{reduction} \mathrm{of} \mathrm{a} \mathrm{platinum} \mathrm{oxide} \mathrm{layer} \mathrm{on} \mathrm{the} \mathrm{platinum}$ electrode (independent of pressure).

\section{THEORETICAL THERMODYNAMIC EFFICIENCY}

The conversion of carbon dioxide to oxygen via Equations 3 or 4 comprises the overall reactions for every method of producing oxygen from Martian carbon dioxide. The smallest amount of energy required for this conversion per mole of oxygen produced can be easily calculated at any temperature. Table 2 presents this data (Chase, 1985) over a wide temperature range, encompassing all the methods discussed above. We have also included the energy to heat up the reactants to the operating temperatures of the conversion and some estimate of heat recovery from products to reactants. There is also a tendency to form $\mathrm{CO}$ at higher temperatures and $\mathrm{C}$ at lower temperatures. If the energy to form $\mathrm{C}$ from the $\mathrm{CO}$ formed in the first step in any reduction is less than the energy to form $\mathrm{CO}$ from $\mathrm{CO}_{2}$, then it is assumed that $\mathbf{C}$ will form. In practice, carbon formation is determined by many other factors than operating temperature, including catalyst, electrode material, operating voltages, electrolyte composition, and other factors. 
Table 2. Thermodynamic Analysis of Oxygen Production by Carbon Dioxide Conversion.

\begin{tabular}{|c|c|c|c|c|c|c|c|c|c|c|}
\hline \multirow[t]{2}{*}{$\begin{array}{r}\text { Temp. } \\
(\mathrm{K})\end{array}$} & \multicolumn{2}{|c|}{$\begin{array}{c}\mathrm{KJ} / \mathrm{Mole} \\
\text { Free Energy }(\Delta \mathrm{G})\end{array}$} & \multirow{2}{*}{$\begin{array}{c}\Delta \mathrm{G} \\
\mathrm{CO}_{2} \Rightarrow \mathrm{CO}\end{array}$} & \multicolumn{2}{|c|}{ Stop $C O \Rightarrow C$ ? } & \multirow{2}{*}{$\begin{array}{l}\Delta \mathrm{G} / \\
\mathrm{mole} \mathrm{O}_{2}\end{array}$} & \multirow{2}{*}{$\frac{\mathrm{Cp}, \mathrm{CO} 2}{\mathrm{~J} / \mathrm{mole}-\mathrm{K}}$} & \multirow{2}{*}{$\begin{array}{r}\Delta \mathrm{H}, \mathrm{CO}_{2} \\
\Rightarrow \text { Temp. } \\
\mathrm{kJ} / \text { mole }\end{array}$} & \multirow{2}{*}{$\frac{\begin{array}{c}\Delta G+\Delta H / \\
\text { mole } O_{2}\end{array}}{k J}$} & \multirow{2}{*}{$\begin{array}{c}70 \% \Delta \mathrm{H} \\
\text { recovery }\end{array}$} \\
\hline & $\mathrm{CO}$ & co? & & $\Delta \mathrm{G}, \mathrm{kJ}$ & $\mathbf{Y} / \mathbf{N}$ & & & & & \\
\hline 30 & & & & & & & 37.2 & 0.1 & 394.4 & \\
\hline 70 & & & & & No & & & 17.7 & & \\
\hline 900 & & & -204 & -12 & No & & 53 & 28 & & \\
\hline 1300 & -226.5 & -396.2 & -169.6 & 56.9 & Yes & -339.3 & 57.1 & 50.1 & 453.6 & 374.4 \\
\hline
\end{tabular}

Some observations are in order. The temperature of the conversion is not a major factor in the energy of the overall conversion. As noted earlier, the materials that can be used in construction of the device affect the durability and reliability of the method, and these choices decrease as the temperature exceeds the abilities of certain materials. This includes most polymers above $473 \mathrm{~K}$, and most base metals above $1073 \mathrm{~K}$. In addition, temperatures above $304 \mathrm{~K}$ exclude the use of liquid $\mathrm{CO}_{2}$. It is also instructive to note how closely a method of conversion approaches the theoretical energy of conversion. For zurconia cells operating at 1.6 volts, the energy of conversion per mole of oxygen produced is $617 \mathrm{~kJ}$. The same amount of energy is consumed to electrolyze water at the same voltage in any process that forms water as a precursor to oxygen production. This value is about $50 \%$ higher than theoretical for the formation of oxygen exclusive of any other energy losses via pumping, heat up of reactants or heat losses through insulation.

\section{CONCLUSIONS}

We have identified several possible alternative methods of oxygen production. We are actively pursuing these concepts to determine the shortcomings and advantages of each. Our goal is to significantly improve upon the characteristics of proposed zirconia cells for oxygen production. To achieve that goal we are looking at electrolytic systems that operate at significantly lower temperatures, preferably below $304 \mathrm{~K}$ to allow the incorporation of liquid $\mathrm{CO}_{2}$ in the electrolyte. Our preliminary results indicate that such a system will have much higher current densities and have simpler cathode construction than a porous gas feed electrode system Such a system could be achieved based on nonaqueous electrolytes or ionic liquids. We are focusing our research on the anode reaction that will produce oxygen from a product generated at the cathode using $\mathrm{CO}_{2}$ as the feed Operation at low temperatures also will open up the full range of polymer and metal materials, allowing a more robust system design to withstand the rigors of flight, landing, and long term unattended operation on the surface of Mars.

\section{REFERENCES}

Amoldi, W. E., "An Electrolytic Process for Carbon Dioxide Separation and Oxygen Reclamation," in Atmosphere in Space Cabins and Closed Environments, edited by K. Kammermeyer, Appleton-Century-Crofts, New York, 1966, pp.76-103.

Aurbach,.D., and Weissman, I., "Nonaqueous Electrochemistry An Overview," in Nonaqueous Electrochemistry, edited by D. Aurbach, Marcel Dekker, Inc, New York, 1999, pp. 46.

Blanchard, L. A., Hancu, D., Beckman, E. J., and Brennecke, J. F., "Green Processing Using lonic Liquids and $\mathrm{CO}_{2}$." Nature, 1999, pp. 28-29.

Chase, M.W., et al., "JANAF Thermochemical Tables, $3^{\text {rd }}$ Edıtion," J. of Physical and Chemical Ref Data, 44, Suppl I(1985).

Janz, G. J., "Molten Carbonate Electrolytes as Acid-Base Solvent Systems,"J Chem. Ed.. 44(10), pp. $581-590$ (1967).

Kanzaki, Y., and Takahashi, M., "The Oxygen Electrode in Fused Lithium Chloride-Potassium Chlonde Eutectic Containing Oxide Ion," Journal of Electroanalytical Chemistry and Interfacial Electrochemistry, 1975, 58, pg 339.

Rogers, R. D., et al., "Room Temperature Ionic Liquids as Altematives to Organic Solvents in Liquid/Liquid Extraction," Proceedings of the 2000 Spring National AIChE meeting (March 5-9, 2000), pp. 200-204.

Taylor, L. T., Supercrittcal Fluid Extraction, John Wiley \& Sons, New York, 1996, pp. 22.

Welton, T., "Room-Temperature Ionic Liquids Solvents for Synthesis and Catalysis," Chemical Review's, pp. A-M. (1999). 